\title{
Keragaman Suara Tonggeret dan Jangkrik di Taman Nasional Gunung Gede Pangrango
}

\author{
Sound Variety of Cicada and Cricket at Gunung Gede \\ Pangrango National Park \\ JUNIARTO GAUTAMA SIMANJUNTAK, MEGA PUTRI AMELYA, FITRI NUR'AENI, RIKA \\ RAFFIUDIN*
}

\author{
Departemen Biologi, Fakultas Matematika dan Ilmu Pengetahuan Alam, Institut Pertanian Bogor, \\ Kampus IPB Dramaga, Bogor 16680
}

Diterima 31 Mei 2020/Disetujui 2 Oktober 2020

\begin{abstract}
Indonesia is a biodiversity country and has much of samples of bioacoustics but there are no bioacoustics data collected and saved to be referred. Bioacoustics is a study of frequency range, sound amplitudo intensity, sound fluctuation, and sound patterns. It is very useful to study more about population presumption and species determination. This insect bioacoustics research is done at Gunung Gede Pangrango National Park and aims to analyse variety of sound frequency of cicada and cricket. Methods which are used are recording the sounds, editing and analyzing the record result with Praat and Raven Lite 2.0 softwares, and analysing the environment. Analysing the sounds which is done is to find miximum frequency, minimum frequency, and average frequency. The result of the sounds analysis is compared to database in Singing Insect of North America (SINA). Environmental analysing includes temperature, air humidity, and light intensity. There are nine cicada sound recording files and twenty four cricket sound recording files. Cicada has high sound characteristic $(9,168.2 \mathrm{~Hz})$ and cricket has low sound characteristic $(3,311.80 \mathrm{~Hz})$. Comparation to Singing Insect of North America (SINA) database shows that the cicada's sound is resemble to Tibicen marginalis and the cricket's sound is resemble to Grylodes sigillatus.
\end{abstract}

Key words: Bioacoustics, Cicada, Cricket, SINA, Sound

\section{PENDAHULUAN}

Indonesia merupakan negara dengan kekayaan sumber daya alam yang melimpah dengan tingkat keragamaan yang tinggi, salah satunya serangga. Bioakustik merupakan suatu ilmu yang mempelajari kisaran frekuensi suara, intensitas amplitudo suara, fluktuasi suara, dan pola-pola suara (Simmonds dan MacLennan 2006). Serangga merupakan salah satu hewan yang mampu menghasilkan dan menerima suara untuk komunikasi. Komunikasi pada beberapa kelompok serangga memiliki peranan penting, umumnya digunakan untuk komunikasi inter atau intra spesies seperti mencari pasangan, peringatan, pertahanan, atau mengkoordinasikan kerja kelompok dan interaksi sosial yang kompleks pada seranggaserangga sosial (Drosopoulos dan Claridge 2006). Serangga memiliki cara menghasilkan suara dan organ penghasil suara yang berbeda-beda tiap jenisnya (Randall et al. 2002). Serangga menghasilkan suara

*Penulis korespondensi:

E-mail: rraffiudin@gmail.com melalui beberapa cara:(1) menggesekkan bagian tubuh serangga dengan bagian tubuh lainnya, misalnya pada jangkrik rumah, Acheta domesticus; (2) menggesekkan bagian tubuh dengan substrat seperti pada belalang daun (katydid), Neoconocephalus retusus (Cocroft dan Rodriguez 2005); (3) menghasilkan suara dari kantung udara seperti pada tonggeret.

Tipe suara yang berbeda pada tiap serangga dapat digunakan dalam pengenalan spesies dan pendugaan populasi di alam. Penelitian bioakustik di Indonesia saat ini masih sangat sedikit yang menguji, khususnya bioakustik serangga. Penelitian ini perlu dilakukan untuk memperkaya database suara, sehingga dapat digunakan untuk pengenalan spesies dan pendugaan populasi. Jangkrik (Ordo Orthoptera) akan mengahasilkan suara dengan membuka dan menutupkan kedua sayap depannya secara serentak dan sebagian besar energi akustik dihasilkan ketika hentakan sayap menutup (closing stroke) (Montealegre et al. 2011). Satu sapuan file pada jangkrik menciptakan satu suara pulse atau syllable. Suara yang dihasilkan tonggeret (Ordo Hemiptera) jantan berasal dari organ spesial yang 
disebut tymbals, yang terletak di sisi atas abdomen. Tymbals merupakan suatu struktur modifikasi dari eksoskeleton yang berbentuk tipis dan dilengkapi dengan aparatus serupa sisir tebal (Hidayati dan Subiantoro 2014). Suara-suara tonggeret dihasilkan dari getaran bebas tymbals saat tonggeret dalam posisi beristirahat dan tertekuk (Pringle 1954). Jenis struktur dan pergerakan timbal serta resonansi yang berbedabeda menyebabkan berbagai variasi suara tonggeret (cicada calls) (Grimaldi dan Engel 2005).

Secara geografis Taman Nasioanl Gunung Gede Pangrango (TNGGP) terletak antara $106^{\circ} 51^{\prime}$ $107^{\circ} 02^{`} \mathrm{BT}$ dan $6^{\circ} 41^{`}-6^{\circ} 51^{\prime} \mathrm{LS}$. Secara administratif Taman Nasional ini termasuk dalam wilayah tiga kabupaten di provinsi Jawa Barat, yaitu Kabupaten Bogor, Kabupaten Sukabumi dan Kabupaten Cianjur. Kawasan hutan Taman Nasional Gunung Gede Pangrango ditetapkan sebagai Taman Nasional berdasarkan Surat Keputusan Menteri Kehutanan RI No SK.3683/Menhut-VII/KUH/2014 tanggal 8 Mei 2014 seluas 24270.80 Ha. Topografi kawasan di Taman Nasional Gunung Gede Pangrango berupa pegunungan dengan ketinggian antara 1,000-3,019 meter di atas permukaan laut. Curah hujan rata-rata berkisar antar 3,000-4,200 mm per tahun. Penelitian ini bertujuan menganalisis perbedaan frekuensi suara pada tonggeret dan jangkrik di kawasan Taman Nasional Gunung Gede Pangrango.

\section{BAHAN DAN METODE}

Metode Pengambilan Data. Mikrofon didekatkan ke arah sumber suara serangga pada saat memulai perekaman. Perekaman dapat dihentikan, jika terdengar suara lain yang mengganggu (noise). Keadaan lingkungan diukur dengan menggunakan alat Environment Meter yang sudah dilengkapi dengan 4 sensor berupa intensitas cahaya, suhu, suara, dan kelembaban.

Analisis Data Akustik. Data suara yang terekam diolah dengan software Praat dan Raven 2.0. Suara diinput ke dalam Praat dengan perintah open read from file dan pilih rekaman sampel yang akan dianalisis, dipotong dan dibersihkan dari noise. Pengaturan frekuensi diatur pada rentang 20 sampai 20,000 Hz. Frekuensi minimum, maksimum, dan rata-rata diperoleh dari menu bar pitch. File suara yang telah bersih disimpan dengan format wav. Kemudian file tersebut dibuka di dalam software Raven 2.0 dengan menu file lalu pilih open sound file untuk diatur kualitas gambar dari gelombang suaranya. Setelah itu file gambar tersebut disimpan dengan format .jpeg. Pada menu file lalu pilih export image of dan all views of window "sound 1". Hasil analisis bioakustik serangga dibandingkan dengan database bioakustik dari penelitian sebelumnya. Suara serangga dibandingkan dengan database yang terdapat di Singing Insect of North America (SINA). Serangga tonggeret dan jangkrik yang diperoleh dari Taman Nasional Gunung Gede Pangrango diidentifikasi hingga tingkat famili, Laboratorium di Divisi Biosistematika dan Ekologi Hewan, Institut Pertanian Bogor menggunakan buku Triplehorn dan Johnson (2005).

\section{HASIL}

Hasil rekaman yang diperoleh berjumlah 9 file rekaman suara tonggeret dan 24 file rekaman suara jangkrik. Rekaman dari tempat penelitian dibawa ke Departemen Biologi Institut Pertanian Bogor untuk dianalisis. Hasil seleksi suara dipaparkan pada Tabel 1. Beberapa file rekaman suara tonggeret dan suara jangkrik didapati memiliki pola yang berbeda. Beberapa file rekaman suara lainnya tidak dapat dianalisis karena terdapat gangguan suara lain (noise). Spesimen tonggeret dan jangkrik yang didapat dari Taman Nasional Gunung Gede Pangrango (TNGGP) juga diidentifikasi hingga tingkat famili. Identifikasi dilakukan pada Laboratorium di Divisi Biosistematika dan Ekologi Hewan, Institut Pertanian Bogor menggunakan buku identifikasi.

Keadaan lingkungan di TNGGP diukur dengan menggunakan alat Environment Meter yang memiliki empat sensor yaitu intensitas cahaya, suhu suara, dan kelembaban udara. Pengambilan suara tonggeret dilakukan pada pagi, siang, dan sore hari, sedangkan suara jangkrik diambil pada malam hari. Kelembaban di sekitar wisma penginapan, lapangan golf, dan danau Mandalawangi sebesar 54.0-54.1\% pada siang hari dan $62.3-73 \%$ pada malam hari. Suhu di sekitar wisma penginapan, lapangan golf, dan danau Mandalawangi yaitu $25.2^{\circ} \mathrm{C}$ pada siang hari dan $17.32^{\circ} \mathrm{C}$ pada malam hari, sedangkan di jalur pendakian air terjun Cibereum bersuhu $20.6^{\circ} \mathrm{C}$ pada siang hari. Intensitas cahaya di parkiran wisma TNGGP cukup tinggi yaitu 1,557, sedangkan di hutan Mandalawangi dan jalur air terjun Cibereum cukup rendah yaitu 937, karena tertutupi kanopi pohon (Tabel 2).

Hasil rekaman suara tonggeret yang dapat dianalisis berjumlah enam file tipe suara tonggeret, yaitu satu tipe suara echeme kontinyu dan lima tipe suara dengan echeme putus-putus (Tabel 3). Tonggeret memiliki karakter suara yang tinggi dengan frekuensi rata-rata dari tipe suara satu sampai tipe suara enam yaitu 9168.20, 9112.07, 9119.37, 6541.51, 4808.89, dan 5881.36 Hz. Frekuensi minimum dari tipe suara satu sampai tipe suara enam yaitu $8831.41,8912.26,8926.47,4142.85$, 
Tabel 1. Database suara, lokasi, dan keadaan lingkungan

\begin{tabular}{lllllllr}
\hline \multirow{2}{*}{ Spesies serangga } & \multirow{2}{*}{ File rekaman } & \multicolumn{1}{c}{ Lokasi } & \multirow{2}{*}{ Waktu } & \multirow{2}{*}{ Tanggal } & \multicolumn{3}{c}{ Data lingkungan } \\
\cline { 6 - 7 } \cline { 5 - 7 } & & & & RH $(\%)$ & Suhu $\left({ }^{\circ} \mathrm{C}\right)$ & Lux \\
\hline Tonggeret & $080101-002$ & Parkiran wisma TNGGP & $09: 11$ & $30 / 07 / 2018$ & 54.0 & 28.4 & 1,557 \\
Tonggeret & $080101-007(1)$ & Hutan Mandalawangi & $10: 14$ & $30 / 07 / 2018$ & 54.1 & 24.4 & 520 \\
Tonggeret & $080101-007(2)$ & Hutan Mandalawangi & $10: 14$ & $30 / 07 / 2018$ & 54.1 & 24.4 & 520 \\
Tonggeret & $080101-013(1)$ & Hutan lebih dalam & $10: 52$ & $30 / 07 / 2018$ & 54.1 & 24.4 & 520 \\
Tonggeret & $080101-013(2)$ & Hutan lebih dalam & $10: 52$ & $30 / 07 / 2018$ & 54.1 & 24.4 & 520 \\
Tonggeret & $080101-066$ & Jalur Cibeureum & $09: 38$ & $31 / 07 / 2018$ & 70.9 & 20.6 & 485 \\
Jangkrik & $080101-026$ & Samping Galeri Korea & $20: 28$ & $30 / 07 / 2018$ & 62.3 & 17.8 & 0 \\
Jangkrik & $080101-029$ & Dekat Danau Mandalawangi & $20: 46$ & $30 / 07 / 2018$ & 62.3 & 17.8 & 0 \\
Jangkrik & $080101-40(1)$ & Belakang wisma asrama & $21: 18$ & $30 / 07 / 2018$ & 73.3 & 17.0 & 0 \\
Jangkrik & $080101-40(2)$ & Belakang wisma asrama & $21: 18$ & $30 / 07 / 2018$ & 73.3 & 17.0 & 0 \\
Jangkrik & $080101-44$ & Lapangan Golf & $21: 29$ & $30 / 07 / 2018$ & 73.3 & 17.0 & 0 \\
Jangkrik & $080101-59$ & Jalur Cibeureum & $08: 54$ & $31 / 07 / 2018$ & 67.1 & 21.5 & 937 \\
\hline
\end{tabular}

Tabel 2. Data lokasi pengambilan suara

\begin{tabular}{lcccc}
\hline Lokasi & $\mathrm{S}$ & $\mathrm{E}$ & Elevasi $(\mathrm{m})$ & Gambar \\
\hline Parkiran wisma TNGGP & $6^{\circ} 44^{\prime} 12^{\prime \prime}$ & $107^{\circ} 00^{\prime} 18^{\prime \prime}$ & 1,326 & \\
\hline
\end{tabular}

Hutan mandalawangi titik ke-2 $\quad 6^{\circ} 44^{\prime} 12^{\prime \prime} \quad 107^{\circ} 00^{\prime} 08^{\prime \prime}$

1,353

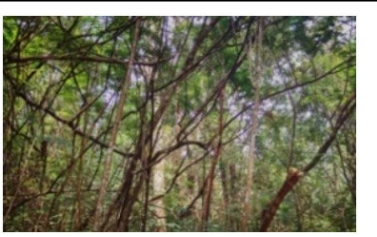

Blok Damar

$6^{\circ} 44^{\prime} 31^{\prime \prime}$

$107^{\circ} 00^{\prime} 19^{\prime \prime}$

1,940

Samping galeri korea

$6^{\circ} 44^{\prime} 36^{\prime \prime}$

$107^{\circ} 00^{\prime} 22^{\prime \prime}$

2,280

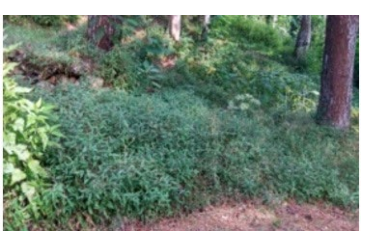

Danau Mandalawangi

$6^{\circ} 44^{\prime} 30^{\prime \prime}$

$107^{\circ} 00^{\prime} 22^{\prime \prime}$

1,890
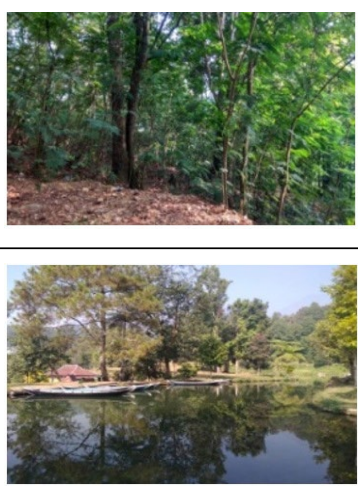
Tabel 2. Lanjutan

\begin{tabular}{|c|c|c|c|c|}
\hline$\underline{\text { Lokasi }}$ & $\mathrm{S}$ & $\mathrm{E}$ & Elevasi (m) & Gambar \\
\hline Lapangan golf & $6^{\circ} 44^{\prime} 32^{\prime \prime}$ & $107^{\circ} 00^{\prime} 16^{\prime \prime}$ & 1,910 & \\
\hline Jalur Cibeureum 1 & $6^{\circ} 44^{\prime} 43^{\prime \prime}$ & $106^{\circ} 59^{\prime} 30^{\prime \prime}$ & 1,537 & \\
\hline Jalur Cibeureum 2 & $6^{\circ} 44^{\prime} 52^{\prime \prime}$ & $106^{\circ} 59^{\prime} 22^{\prime \prime}$ & 1,582 & \\
\hline
\end{tabular}

Tabel 3. Tipe suara, karakter suara, durasi, dan echeme tonggeret

\begin{tabular}{cccccccc}
\hline Tipe suara & \multirow{2}{*}{ Nama file } & Tanggal & Waktu (WIB) & Karakter suara & Durasi rekaman & Echeme & $\begin{array}{r}\text { Jumlahecheme } \\
\text { dalam } 10 \text { detik }\end{array}$ \\
\hline 1 & $080101-002$ & $30 / 07 / 2018$ & $09: 11$ & Tinggi & $00: 39$ & Kontinyu & - \\
2 & $080101-007(1)$ & $30 / 07 / 2018$ & $10: 14$ & Tinggi & $00: 20$ & Putus & 10 \\
3 & $080101-007(2)$ & $30 / 07 / 2018$ & $10: 14$ & Tinggi & $00: 20$ & Putus & 3 \\
4 & $080101-013(1)$ & $30 / 07 / 2018$ & $10: 52$ & Tinggi & $01: 31$ & Putus & 14 \\
5 & $080101-013(2)$ & $30 / 07 / 2018$ & $10: 52$ & Tinggi & $01: 31$ & Putus & 28 \\
6 & $080101-066$ & $31 / 07 / 2018$ & $09: 38$ & Tinggi & $00: 17$ & Putus & 4 \\
\hline
\end{tabular}

4518.47, dan 4093.97 Hz. Frekuensi maksimum dari tipe suara satu sampai tipe suara enam yaitu 9496.64, 9331.99, 9296.71, 9781.58, 5261.36, dan $9690.80 \mathrm{~Hz}$ (Tabel 4).

Hasil identifikasi serangga tonggeret dan jangkrik yang didapat dari Taman Nasional Gunung Gede Pangrango menunjukan bahwa tonggeret tersebut termasuk ke dalam Famili Cicadidae dan jangkrik yang didapat termasuk ke dalam Famili Gryllidae.

Hasil rekaman suara jangkrik yang dapat dianalisis berjumlah enam tipe suara, seluruhnya bertipe suara echeme putus-putus (Tabel 5). Frekuensi rata-rata dari tipe suara satu sampai tipe suara enam yaitu 3311.80, 4945.59, 5458.25, 3261.52, 6280.74, dan 6952.71 Hz. Frekuensi minimum dari tipe suara satu sampai tipe suara enam yaitu 3106.69, 4895.36, 2565.50, 1370.97, 6162.33, dan 3994.67 Hz. Frekuensi maksimum dari tipe suara satu sampai tipe suara enam yaitu $3382.75,4980.64,6438.27,3866.88,6404.31$, dan $9912.02 \mathrm{~Hz}$ (Tabel 6).

Hasil analisis suara juga dibandingkan dengan suara yang tersedia di database Singing Insects of North America (SINA). Tonggeret dengan file rekaman 080101-013(2) memiliki frekuensi (ratarata, minimal, dan maksimal) yang mendekati adalah tonggeret Tibicen marginalis. Suara jangkrik dengan file rekaman 080101-044 juga memiliki frekuensi (rata-rata, minimal, dan maksimal) adalah jangkrik Gryllodes sigillatus.

\section{PEMBAHASAN}

Frekuensi data suara tonggeret dan jangkrik yang didapat sangat beragam. Hal tersebut dipengaruhi oleh tipe spesies dan faktor lingkungan seperti kelembapan, suhu udara, dan intensitas cahaya. Karakteristik suara didasarkan pada pendengaran manusia secara subyektif. Jangkauan suara yang dapat didengar oleh telinga manusia yaitu frekuensi 20-20,000 Hz. Bunyi-bunyi yang muncul pada frekuensi di bawah $20 \mathrm{~Hz}$ disebut bunyi infrasonik, sedangkan yang muncul di atas $20,000 \mathrm{~Hz}$ disebut bunyi ultrasonik. Rentang 20 sampai dengan 20,000 $\mathrm{Hz}$ bunyi masih dibedakan menjadi bunyi dengan frekuensi rendah (dibawah $1,000 \mathrm{~Hz}$ ), frekuensi sedang $(1,000$ sampai $4,000 \mathrm{~Hz})$ dan frekuensi tinggi (di atas 4,000 Hz) (Mediastika dan Christina 2009). 
Perbandingan analisis suara tonggeret di TNGGP dengan suara tonggeret di Kebun Raya Bogor menunjukan bahwa tipe suara 5 yang memiliki karakter suara tinggi, memiliki frekuensi (minimal dan maksimum) mendekati analisis suara tonggeret yang telah dilakukan oleh Sofyan (2016) di Kebun Raya Bogor (Tabel 7). Namun analisis suara tonggeret di TNGGP tidak menunjukan kesamaan ritme dan pola suara dengan suara tonggeret di Kebun Raya Bogor. Perbandingan analisis suara jangkrik di TNGGP dengan hasil analisis yang telah dilakukan Laksono et al. (2015) di Waduk Jatiluhur menunjukan tiga tipe suara yang memiliki karakter suara rendah dan frekuensi (rata-rata, minimal, dan maksimum) mendekati analisis suara jangkrik (Tabel 8). Namun, analisis suara jangkrik di TNGGP tidak menunjukan kesamaan ritme dan pola suara dengan suara jangkrik di Waduk Jatiluhur.

Hasil perbandingan dengan analisis suara jangkrik yang telah dilakukan Rifdah et al. (2017) di Taman Bunga Mekarsari menunjukkan satu tipe suara yang memiliki karakter suara rendah dengan gambar oskilogram dan spektogram, serta frekuensi (rata-rata, minimum, dan maksimum) yang mendekati analisis suara jangkrik yang dilakukan di TNGGP sedangkan satu tipe suara yang memiliki karakter suara tinggi hanya memiliki frekuensi

Tabel 4. Frekuensi suara tonggeret hasil analisis dengan program Praat

\begin{tabular}{clccc}
\hline Tipe suara & \multicolumn{1}{c}{ Nama file } & $\begin{array}{c}\text { F mean } \\
(\mathrm{Hz})\end{array}$ & $\begin{array}{c}\text { F min } \\
(\mathrm{Hz})\end{array}$ & $\begin{array}{c}\text { F max } \\
(\mathrm{Hz})\end{array}$ \\
\hline 1 & $080101-002$ & 9168.20 & 8831.41 & 9496.64 \\
2 & $080101-007(1)$ & 9112.07 & 8912.26 & 9331.99 \\
3 & $080101-007(2)$ & 9119.37 & 8926.47 & 9296.71 \\
4 & $080101-013(1)$ & 6541.51 & 4142.85 & 9781.58 \\
5 & $080101-013(2)$ & 4808.89 & 4518.47 & 5261.36 \\
6 & $080101-066$ & 5881.36 & 4093.97 & 9690.80 \\
\hline
\end{tabular}

(rata-rata dan maksimum) yang mendekati data analisis (Tabel 9). Analisis suara dari tonggeret dan jangkrik dari TNGGP dapat menjadi acuan perbandingan frekuensi suara serangga untuk penelitian bioakustik selanjutnya. Selain itu, penelitian mengenai suara tonggeret dan jangkrik di TNGGP dapat menyumbang database bioakustik serangga di Indonesia yang saat ini masih jarang diteliti.

Hasil bioakustik di Taman Nasional Gunung Gede Pangrango (TNGGP) yang dapat dianalisis berjumlah enam file rekaman suara tonggeret dan enam file rekaman suara jangkrik. Keunikan hasil penelitian di TNGGP yaitu kawasan tersebut memiliki lingkungan yang masih alami sehingga populasi serangga seperti tonggeret banyak dijumpai. Tonggeret memiliki karakter suara yang lebih tinggi dari suara jangkrik. Suara tersebut dibandingkan dengan suara yang terdapat pada database Singing Insects of North America (SINA) (Tabel 10). Berdasarkan hasil perbandingan frekuensi suara tonggeret TNGGP yang dianalisis dengan database SINA, mendapatkan spesies yang mendekati adalah tonggeret Tibicen marginalis. Hasil perbandingan frekuensi suara jangkrik dengan database SINA mendapatkan spesies yang mendekati adalah jangkrik Gryllodes sigillatus.

Tabel 6. Frekuensi suara jangkrik hasil analisis dengan program Praat

\begin{tabular}{clccc}
\hline Tipe suara & \multicolumn{1}{c}{ Nama file } & $\begin{array}{c}\text { F mean } \\
(\mathrm{Hz})\end{array}$ & $\begin{array}{c}\text { F min } \\
(\mathrm{Hz})\end{array}$ & $\begin{array}{c}\text { F max } \\
(\mathrm{Hz})\end{array}$ \\
\hline 1 & $080101-026$ & 3311.80 & 3106.69 & 3382.75 \\
2 & $080101-029$ & 4945.59 & 4895.36 & 4980.64 \\
3 & $080101-40(1)$ & 5458.25 & 2565.50 & 6438.27 \\
4 & $080101-40(2)$ & 3261.52 & 1370.97 & 3866.88 \\
5 & $080101-44$ & 6280.74 & 6162.33 & 6404.31 \\
6 & $080101-59$ & 6952.71 & 3994.67 & 9912.02 \\
\hline
\end{tabular}

Tabel 5. Tipe suara, karakter suara, durasi, dan echeme jangkrik

\begin{tabular}{clcccccc}
\hline Tipe suara & \multirow{2}{*}{ Nama file } & Tanggal & Waktu(WIB) & Karakter suara & Durasi rekaman & Echeme & $\begin{array}{r}\text { Jumlahecheme } \\
\text { dalam 10 detik }\end{array}$ \\
\hline 1 & $080101-026$ & $30 / 07 / 2018$ & $20: 28$ & Rendah & $00: 34$ & Putus & 2 \\
2 & $080101-029$ & $30 / 07 / 2018$ & $20: 46$ & Rendah & $00: 56$ & Putus & 4 \\
3 & $080101-40(1)$ & $30 / 07 / 2018$ & $21: 18$ & Rendah & $01: 08$ & Putus & 20 \\
4 & $080101-40(2)$ & $30 / 07 / 2018$ & $21: 18$ & Rendah & $01: 08$ & Putus & 5 \\
5 & $080101-44$ & $30 / 07 / 2018$ & $20: 29$ & Tinggi & $01: 07$ & Putus & - \\
6 & $080101-59$ & $31 / 07 / 2018$ & $08: 54$ & Rendah & $02: 07$ & Putus & 3 \\
\hline
\end{tabular}

Tabel 7. Perbandingan data suara tonggeret TNGGP dengan suara tonggeret di Kebun Raya Bogor

\begin{tabular}{|c|c|c|c|c|c|c|c|c|}
\hline \multirow{2}{*}{ Karakter suara } & \multicolumn{4}{|c|}{ Data suara tonggeret TNGGP } & \multicolumn{4}{|c|}{ Data suara tonggeret Kebun Raya Bogor (Sofyan 2016) } \\
\hline & Tipe suara & $\begin{array}{c}\text { F mean } \\
(\mathrm{Hz})\end{array}$ & $\begin{array}{c}\text { F min } \\
(\mathrm{Hz})\end{array}$ & $\begin{array}{c}\text { F max } \\
(\mathrm{Hz})\end{array}$ & Tipe suara & $\begin{array}{c}\text { F mean } \\
(\mathrm{Hz})\end{array}$ & $\begin{array}{c}\mathrm{F} \min \\
(\mathrm{Hz})\end{array}$ & $\begin{array}{c}\mathrm{F} \max \\
(\mathrm{Hz})\end{array}$ \\
\hline Tingg & 5 & 4808.89 & 4518.47 & 5261.36 & & - & 4370.5 & 5123.6 \\
\hline Tinggi & 5 & 4808.89 & 4518.47 & 5261.36 & Dundubia vaginata & - & 2650.0 & 3313.7 \\
\hline
\end{tabular}


Tabel 8. Perbandingan suara jangkrik TNGGP dengan suara jangkrik di Waduk Jatiluhur

\begin{tabular}{|c|c|c|c|c|c|c|c|c|}
\hline \multirow{2}{*}{ Karakter suara } & \multicolumn{4}{|c|}{ Data suara jangkrik TNGGP } & \multicolumn{4}{|c|}{ Data suara jangkrik Waduk Jatiluhur (Laksono et al. 2015) } \\
\hline & Tipe suara & $\begin{array}{c}\text { F mean } \\
(\mathrm{Hz})\end{array}$ & $\begin{array}{c}\text { F min } \\
(\mathrm{Hz})\end{array}$ & $\begin{array}{c}\text { F max } \\
(\mathrm{Hz})\end{array}$ & Tipe suara & $\begin{array}{c}\text { F mean } \\
(\mathrm{Hz})\end{array}$ & $\begin{array}{c}\text { F min } \\
(\mathrm{Hz})\end{array}$ & $\begin{array}{c}\text { F max } \\
(\mathrm{Hz})\end{array}$ \\
\hline Rendah & 1 & 9168.20 & 8831.41 & 9496.64 & 2 & 8945.33 & 8221.79 & 9628.22 \\
\hline Rendah & 5 & 4808.89 & 4518.47 & 5261.36 & 1 & 4739.00 & 4574.55 & 4904.72 \\
\hline Rendah & 6 & 5881.36 & 4093.97 & 9690.80 & 11 & 5710.71 & 5601.96 & 5803.30 \\
\hline
\end{tabular}

Tabel 9. Perbandingan suara jangkrik TNGGP dengan suara jangkrik di Taman Bunga Mekarsari

\begin{tabular}{|c|c|c|c|c|c|c|c|c|}
\hline \multirow{2}{*}{ Karakter suara } & \multicolumn{4}{|c|}{ Data suara jangkrik TNGGP } & \multicolumn{4}{|c|}{ Data suara jangkrik Taman Buah Mekarsari (Rifdah et al. 2017) } \\
\hline & Tipe suara & $\begin{array}{c}\text { F mean } \\
(\mathrm{Hz})\end{array}$ & $\begin{array}{c}\mathrm{F} \min \\
(\mathrm{Hz})\end{array}$ & $\begin{array}{c}\text { F max } \\
(\mathrm{Hz})\end{array}$ & Tipe suara & $\begin{array}{c}\text { F mean } \\
(\mathrm{Hz})\end{array}$ & $\begin{array}{c}\begin{array}{c}\text { F min } \\
(\mathrm{Hz})\end{array} \\
\end{array}$ & $\begin{array}{c}\text { F max } \\
(\mathrm{Hz})\end{array}$ \\
\hline Rendah & 4 & 6541.51 & 4142.85 & 9781.58 & 13 & 7896 & 3373 & 10408 \\
\hline Tinggi & 5 & 4808.89 & 4518.47 & 5261.36 & 11 & 4819 & 2181 & 5120 \\
\hline
\end{tabular}

Tabel 10. Perbandingan suara hasil analisis dengan SINA

\begin{tabular}{llcccc}
\hline $\begin{array}{l}\text { Spesies } \\
\text { serangga }\end{array}$ & Sumber & \multicolumn{1}{c}{$\begin{array}{c}\text { File } \\
\text { rekaman }\end{array}$} & $\begin{array}{c}\text { F mean } \\
(\mathrm{Hz})\end{array}$ & $\begin{array}{c}\text { F min } \\
(\mathrm{Hz})\end{array}$ & $\begin{array}{c}\text { F max } \\
(\mathrm{Hz})\end{array}$ \\
\hline Tonggerer & Rekaman & 080101-013(2) & 4808.89 & 4518.47 & 5261.36 \\
& SINA & 852sl.wav & 5043.59 & 4934.58 & 5335.26 \\
Jangkrik & Rekaman & 080101-044 & 6280.74 & 6162.33 & 6404.31 \\
& SINA & 501ss2.wav & 6178.91 & 6099.15 & 6221.86 \\
\hline
\end{tabular}

\section{UCAPAN TERIMA KASIH}

Penyelesaian karya tulis ini tak lepas dari bantuan yang telah diberikan oleh berbagai pihak. Kepada Dr. Ir. Rika Raffiudin, M.Si. sebagai dosen pembimbing, penulis mengucapkan terima kasih yang sebesarbesarnya atas kesabaran dalam membimbing hingga selesainya tulisan ini. Kepada Dr. Ir. Tania June, M.Sc. selaku Ketua Divisi Agrometeorologi, Departemen Geofisika dan Meteorologi, Fakultas Matematika dan Ilmu Pengetahuan Alam atas kesediannya untuk meminjamkan "Environment Meter" (1 alat dengan 4 sensor) kepada penulis selama proses pengambilan data. Terima kasih juga penulis sampaikan kepada Panji Laksono selaku asisten dari Divisi Fungsi dan Perilaku Hewan (Departemen Biologi) yang telah membantu penulis selama di lapang, serta telah memberikan masukan yang sangat membantu. Terima kasih penulis sampaikan kepada Tiara Sayusti, S.Si. (Program Magister Ps Biosains Hewan, Departemen Biologi IPB), sebagai asisten studi lapang yang telah membantu penulis selama di laboratorium. Kepada seluruh dosen, staf dan mahasiswa dari Departemen Biologi IPB yang telah menjadi bagian terpenting dalam Studi Lapang 2018. Serta kepada para staf di Taman Nasional Gunung Gede Pangrango, terima kasih atas dukungan dan kerja samanya dalam pembuatan karya tulis ini.

\section{DAFTAR PUSTAKA}

Cocroft R, Rodríguez RL. 2005. The behavioral ecology of insect vibrational communication. BioScience 55:323-334.

Drosopoulos S, Claridge MF. 2006. Insect Sound and Communication: Physiology, Behaviour, Ecology, and Evolution. New York: Taylor and Francis Group.

Grimaldi D, Engel MS. 2005. Evolution of The Insect. New York: Cambridge University Press.

Hidayati S, Subiantoro AW. 2014. Profil bioakustik nyanyian cicada (Cicadidae) di lingkungan FMIPA Universitas Negeri Yogyakarta. Jurnal Sains Dasar 3:39-47.

Laksono P et al. 2015. Frekuensi suara jangkrik di kawasan Waduk Jatiluhur. Bogor: Institut Pertanian Bogor.

Mediastika E, Christina. 2009. Material Akustik Pengendali Kualitas Bunyi. Jakarta: Erlangga.

Montealegre F et al. 2011. Sound radiation and wing mechanics in stridulating field crickets (Orthoptera: Gryllidae). Journal of Experimental Biology 214:2105-2117.

Pringle JWS. 1954. A physiological analysis of cicada song. Journal of Experimental Biology 31:526-560.

Randall D et al. 2002. Eeckert Animal Physiology: Mechanism and Adaptations. New York: W.H Freeman and Co.

Rifdah N et al. 2017. Pola dan frekuensi suara jangkrik, tonggeret, dan belalang di kawasan Taman Buah Mekarsari. Bogor: Institut Pertanian Bogor.

Simmonds J, MacLennan D. 2006. Fisheries Acoustics: Theory and Practice,Second Edition. London: Wiley-Blackwell.

Sofyan F. 2016. Karakteristik bioakustik tonggeret (Hemiptera : Cicadidae) di Kebun Raya Bogor [Skripsi]. Bogor: Institut Pertanian Bogor.

Triplehorn CH, Johnson NF. 2005. Borror and Delong's Introduction to the Study of Insects. Seventh Edition. America: Thompson Brook. 